\title{
Dexmedetomidine as an adjuvant to bupivacaine in interscalene block for postoperative pain management
}

\author{
Amulya $\mathrm{N}^{1}$, Nilambaree S Adke ${ }^{2 *}$, Mrunmayee S Adke $^{3}$, V V Kulkarni ${ }^{4}, \mathrm{P} \mathrm{I} \mathrm{Agrawal}^{5}$ \\ ${ }^{1}$ Consultant, ${ }^{2}$ Associate Professor, ${ }^{3}$ Intern, ${ }^{4}$ Associate Professor, ${ }^{5}$ Professor \& HOD, Department of Anesthesia, Dr V. M. Government \\ Medical College, Solapur, INDIA. \\ Email: doctorneelambaree@gmail.com
}

Abstract Background: Dexmedetomidine is a highly selective alpha-2 adrenergic agonist, sedative, analgesic effects with reduced analgesic requirements. Bupivacaine is a long acting local anaesthetic. Both are used in combination for better postoperative pain management in regional block. Aim: To evaluate dexmedetomidine as an adjuvant to bupivacaine in interscalene block for postoperative pain management. Material and Methods: A total of 80 patients of ASA I, and II undergoing elective various upper limb surgeries were included in the study. Patients were divided into 2 groups of 40 each. Group A received $0.25 \%$ Bupivacaine and Group B received $0.25 \%$ Bupivacaine $+1 \mu \mathrm{g} / \mathrm{kg}$ dexmedetomidine. Visual analogue score was used to grade severity of pain. Results: Even after ten hours post op (600 min) half of the patient (16) in Group B did not required analgesics, whereas all the patients required analgesics in Group A. This shows that Group B had better analgesia post operatively as compared to Group A. Conclusion: Addition of dexmedetomidine to bupivacaine as an adjuvant is a promising option to enhance their effectiveness. So, the patient remains comfortable in the postoperative period with considerable therapeutic benefit and without any potential side effects.

Key Words: Interscalene block, Dexmedetomidine, bupivacaine, visual analogue score

\section{*Address for Correspondence:}

Dr Adke Nilambaree Santosh, 1/1, Adke Hospital, Bedar Pool, North Sadar Bazar. Solapur. 413003, Maharashtra, INDIA.

Email: doctorneelambaree@gmail.com

Received Date: 12/09/2019 Revised Date: 02/12/2019 Accepted Date: 29/12/2019

DOI: https://doi.org/10.26611/10151515

This work is licensed under a Creative Commons Attribution-NonCommercial 4.0 International License. (cc)) BY-NC

\begin{tabular}{|l|l|}
\hline \multicolumn{2}{|c|}{ Access this article online } \\
\hline Quick Response Code: & \multirow{2}{*}{ Website: } \\
www.medpulse.in \\
\cline { 2 - 2 }
\end{tabular}

\section{INTRODUCTION}

Pain is an unpleasant, sensory and emotional experience associated with actual or potential tissue damage. Pain after orthopaedic surgery can be intense. ${ }^{1}$ In particular, managing pain after shoulder procedures poses a challenge to both anaesthesiologists and orthopaedic surgeons. In an effort to improve analgesia and facilitate mobilization, regional anaesthesia in the form of an interscalene approach to the brachial plexus is often used either as an adjunct to general anaesthesia or as the primary anaesthetic. Peripheral nerve blockade is now a wellaccepted component of comprehensive anaesthetic care. Its role has expanded from the operating suite into area of postoperative and chronic pain management. ${ }^{2}$ Dexmedetomidine is a highly selective alpha- 2 adrenergic agonist. Alpha-2 adrenergic agonists have been the focus of interest for their sedative, analgesic, perioperative sympatholytic and cardiovascular stabilizing effects with reduced analgesic requirements. Dexmedetomidine is being used in intravenous regional anaesthesia, intravenous sedation and analgesia for intubated and mechanically ventilated patients in intensive care units, and non-intubated patients for surgical and other procedures. It has been reported to improve the quality of intrathecal and epidural anaesthesia. Its use in peripheral nerve blocks has recently been described. ${ }^{2,3}$ Bupivacaine is a long acting local anaesthetic. Due to its long duration of 
action and combined with its high quality sensory anaesthesia relative to motor blockade it has been the most commonly used local anaesthetic for peripheral nerve blocks. The present study was conducted to evaluate dexmedetomidine as an adjuvant to bupivacaine in interscalene block for postoperative pain management.

\section{MATERIAL AND METHODS}

The study included 80 patients undergoing elective surgeries of the upper limb.

\section{Study design}

It was a prospective randomized double blind interventional type of the hospital based controller study.

\section{Sample size}

A total of 80 patients of ASA I, and II undergoing elective various upper limb surgeries were included in the study. Patients were divided into 2 groups of 40 each (Group A and Group B).

Group A: Received Interscalene brachial plexus block with $30 \mathrm{ml}$ of $0.25 \%$ Bupivacaine $+1 \mathrm{ml}$ of normal saline a total of $31 \mathrm{ml}$.

Group B: Received Interscalene brachial plexus block with $30 \mathrm{ml}$ of $0.25 \%$ Bupivacaine $+1 \mu \mathrm{g} / \mathrm{kg}$ dexmedetomidine + normal saline to make total of $31 \mathrm{ml}$. Inclusion criteria

- Age: $18-65$ years

- American society of anaesthesiologist (ASA) physical status- I and II

- Elective upper limb surgeries istep?

Exclusion criteria

- Patient refusal for procedure

- Patient with Bleeding disorders or on anticoagulants

- Neurological deficits involving brachial plexus

- Patients with allergy to local anaesthetics

- Local infection at the injection site

- Patients on any sedatives or antipsychotics

These patients were randomly divided into two groups each of 40 patients by lottery method. This was done and the medications were prepared by another person, that way the patient and the person doing the study were unaware of the group a particular patient had been allotted.

\section{Procedure}

Written informed consent was obtained from each participating patient in their own language before enrolling into the study after complete explanation of the study protocol and procedure. The Interscalene groove was located by sliding the fingers laterally from under the sternocleidomastoid muscle. The index and middle finger of the left hand remain in the groove, and a small skin wheal is made over the groove and between these fingers. The block needle was then inserted perpendicularly to all planes and slightly caudal. The needle was advanced through the sheath, at which time a fascial "pop" may be felt. As one of the roots of the plexus is neared, the muscles supplied by that root will be stimulated to contract. Usually a current of 1-1.5 mA is adequate to start searching. Once an appropriate muscle contraction is seen, the current is decreased slowly to determine the threshold (the lowest current at which stimulation still occurs). The closer the needle is to a nerve, the lower the threshold will be. Some practitioners generally search for a current of less than 0.5 $\mathrm{mA}$. If the threshold current obtained is higher than desired, the needle is repositioned. Once the desired response is found, the needle is stabilized and $30 \mathrm{~mL}$ of local anesthetic is injected. As with all nerve blocks, injection should be slow, in increments and with frequent aspiration. If the threshold current is $0.2 \mathrm{~mA}$ or less, if injection pressure is high, or if the patient has a paresthesia during needle placement or injection, the needle is pulled back slightly because of concern of intraneural placement. An acceptable motor response would be one involving the deltoid muscle or any muscle in the arm or hand. If the needle is placed lateral and posterior to the middle scalene, it is possible to stimulate the accessory, dorsal scapular, and long thoracic nerves, which results in stimulation of the trapezius, rhomboids, and serratus anterior muscles, respectively. If the needle is placed between the anterior scalene and the sternocleidomastoid muscle (ie, too anterior), the phrenic nerve is frequently stimulated, causing contraction of the diaphragm (ie, hiccupping). Thus, these undesired twitches can help guide the practitioner in repositioning of the needle.

Visual analogue score

This scale is used for grading severity of pain. It is graded on a scale of $0-10$. 0 : being no pain at allispip 10 : being the worst pain imaginable. Time between onset of complete block to time of first request for analgesia i.e. VAS $>4$. 0 1: good analgesia.sspi] 1-4: moderate analgesia. 4-7: mild analgesia. 7-10: no analgesia. Rescue analgesics was given in the form of injection diclofenac $(1.5 \mathrm{mg} / \mathrm{kg})$ intravenously when VAS score is $>4$ on patients request and the time of administration was noted.

Statistical analysis

The independent samples $t$-test procedure compares means for two groups of cases. SPSS for windows (version 21.0, SPSS Inc., Chicago, IL, USA) was employed for data analysis. $P<0.05$ was considered as significant. Ethical Approval was taken from Institutional Ethical committee. 


\section{RESULTS}

The mean age in Group A was 37.875 years and Group B was 38.025 years. In group A there were 33 males and 7 females whereas group B included 30 males and 10 females. Both groups were comparable in terms of age and sex. Independent two sample T-test was applied. The difference was not statistically significant ( $\mathrm{P}$ value $=0.9663$ ).

\begin{tabular}{cccc} 
Table 1: Type and Distribution of various surgeries in Group A and Group B \\
\hline Surgery/ Procedure & Group A & Group B & Z-value \\
\hline Humerus fracture & 23 & 21 & 0 \\
Supracondylar Humerus fracture & 6 & 14 & -2.065 \\
Lateral condyle fracture & 2 & 0 & 1.43 \\
Medial condyle fracture & 3 & 1 & 1.026 \\
Olecranon fracture & 4 & 4 & -0.84 \\
Radial head excision & 2 & 0 & 1.43 \\
\hline Total & 40 & 40 & \\
\hline
\end{tabular}

The two groups were well matched with respect to type of surgical procedures. Two groups were comparable and no statistical significance found ( $\mathrm{P}$ value $>0.05$ ). Mean Duration of surgery in Group A was 101.35 minutes and Group B was 102.75 minutes. There was no significant difference between mean duration of surgery (in minutes) in group A and Group

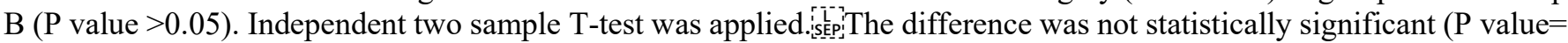
$0.593)$.

Table 2: Comparison of median VAS in Group A and Group B

\begin{tabular}{cccc}
\hline & \multicolumn{2}{c}{ Median VAS } & P value \\
\cline { 2 - 3 } & Group A & Group B & \\
\hline $30 \mathrm{~min}$ & 0 & 0 & NA \\
$60 \mathrm{~min}$ & 0 & 0 & NA \\
$90 \mathrm{~min}$ & 1 & 0 & 0.03 \\
$120 \mathrm{~min}$ & 2 & 0 & $<0.0001$ \\
$180 \mathrm{~min}$ & 3 & 0 & $<0.0001$ \\
$240 \mathrm{~min}$ & 4 & 1 & $<0.0001$ \\
$300 \mathrm{~min}$ & 4 & 1 & $<0.0001$ \\
$360 \mathrm{~min}$ & 5 & 1 & $<0.0001$ \\
$420 \mathrm{~min}$ & 5 & 2 & $<0.0001$ \\
$480 \mathrm{~min}$ & 6 & 3 & $<0.0001$ \\
$540 \mathrm{~min}$ & 6 & 3 & $<0.0001$ \\
$600 \mathrm{~min}$ & 6 & 3 & $<0.0001$ \\
\hline
\end{tabular}

Table 2 shows that there is significant difference between median VAS score in Group A and Group B. Group B has significantly less VAS score compared to Group A ( $<<0.0001)$. Mann Whitney U test was applied; The difference is statistically highly significant from post op 30th to 600th $\min (\mathrm{p}<0.0001)$. P value of $<0.001$ was considered as highly significant.

Table 3: Comparison of visual analogue scale (VAS) score in both groups (in time trends)

\begin{tabular}{|c|c|c|c|c|c|c|c|c|c|c|}
\hline \multirow{2}{*}{\multicolumn{2}{|c|}{ Post op in min }} & \multicolumn{9}{|c|}{ Visual analogue score } \\
\hline & & \multirow{2}{*}{$\begin{array}{c}0 \\
40\end{array}$} & \multirow{2}{*}{$\begin{array}{l}1 \\
0\end{array}$} & \multirow{2}{*}{$\begin{array}{l}2 \\
0\end{array}$} & \multirow{2}{*}{$\begin{array}{l}3 \\
0\end{array}$} & \multirow{2}{*}{$\begin{array}{l}4 \\
0\end{array}$} & \multirow{2}{*}{$\begin{array}{l}5 \\
0\end{array}$} & \multirow{2}{*}{$\begin{array}{l}6 \\
0\end{array}$} & \multirow{2}{*}{$\begin{array}{l}7 \\
0\end{array}$} & \multirow{2}{*}{$\begin{array}{c}\text { Total } \\
40\end{array}$} \\
\hline $30 \mathrm{~min}$ & Group A & & & & & & & & & \\
\hline so mIII & Group B & 40 & 0 & 0 & 0 & 0 & 0 & 0 & 0 & 40 \\
\hline \multirow{2}{*}{$60 \mathrm{~min}$} & Group A & 40 & 0 & 0 & 0 & 0 & 0 & 0 & 0 & 40 \\
\hline & Group B & 40 & 0 & 0 & 0 & 0 & 0 & 0 & 0 & 40 \\
\hline \multirow{2}{*}{$90 \mathrm{~min}$} & Group A & 3 & 28 & 9 & 0 & 0 & 0 & 0 & 0 & 40 \\
\hline & Group B & 40 & 0 & 0 & 0 & 0 & 0 & 0 & 0 & 40 \\
\hline \multirow{2}{*}{$120 \mathrm{~min}$} & Group A & 0 & 4 & 30 & 6 & 0 & 0 & 0 & 0 & 40 \\
\hline & Group B & 40 & 0 & 0 & 0 & 0 & 0 & 0 & 0 & 40 \\
\hline \multirow{2}{*}{$180 \mathrm{~min}$} & Group A & 0 & 1 & 3 & 26 & 10 & 0 & 0 & 0 & 40 \\
\hline & Group B & 40 & 0 & 0 & 0 & 0 & 0 & 0 & 0 & 40 \\
\hline \multirow{2}{*}{$240 \mathrm{~min}$} & Group A & 0 & 0 & 0 & 3 & 37 & 0 & 0 & 0 & 40 \\
\hline & Group B & 4 & 36 & 0 & 0 & 0 & 0 & 0 & 0 & 40 \\
\hline $300 \mathrm{~min}$ & Group A & 0 & 0 & 0 & 0 & 40 & 0 & 0 & 0 & 40 \\
\hline
\end{tabular}




\begin{tabular}{|c|c|c|c|c|c|c|c|c|c|c|}
\hline & Group B & 1 & 33 & 6 & 0 & 0 & 0 & 0 & 0 & 40 \\
\hline \multirow{2}{*}{$360 \mathrm{~min}$} & Group A & 0 & 0 & 0 & 0 & 0 & 40 & 0 & 0 & 40 \\
\hline & Group B & 0 & 32 & 7 & 1 & 0 & 0 & 0 & 0 & 40 \\
\hline \multirow{2}{*}{$420 \mathrm{~min}$} & Group A & 0 & 0 & 0 & 0 & 0 & 27 & 13 & 0 & 40 \\
\hline & Group B & 0 & 0 & 37 & 3 & 0 & 0 & 0 & 0 & 40 \\
\hline \multirow[t]{2}{*}{$480 \mathrm{~min}$} & Group A & 0 & 0 & 0 & 0 & 0 & 16 & 24 & 0 & 40 \\
\hline & Group B & 0 & 0 & 14 & 26 & 0 & 0 & 0 & 0 & 40 \\
\hline \multirow[t]{2}{*}{$540 \mathrm{~min}$} & Group A & 0 & 0 & 0 & 0 & 0 & 1 & 31 & 8 & 40 \\
\hline & Group B & 0 & 0 & 8 & 32 & 1 & 0 & 0 & 0 & 40 \\
\hline \multirow[t]{2}{*}{$600 \mathrm{~min}$} & Group A & 0 & 0 & 0 & 0 & 0 & 0 & 6 & 34 & 40 \\
\hline & Group B & 0 & 0 & 2 & 33 & 1 & 0 & 0 & 0 & 40 \\
\hline
\end{tabular}

Post op 30 and 60 min median VAS in Group A and Group $\mathrm{B}$ was 0 . All 40 patients VAS was 0 at 30 and $60 \mathrm{~min}$ in both groups. At 90th min median VAS in Group A was 3 and 0 in Group B. In Group A 28 patients had VAS 1 and 9 patients had VAS 2, in Group B all 40 patients had VAS 0 . In Group B up to 3 hours post op (i.e. at $180 \mathrm{~min}$ ) none of the patients complained of pain i.e. all the patients were pain free (VAS 0), whereas in Group A pain had started appearing in almost all the patients they were towards analgesic requirement. Up to $6 \mathrm{hrs}$ postop $(360 \mathrm{~min})$ no patient in Group B required analgesics whereas in Group A more than half of the patients $(65 \%)$ required analgesic. Even after ten hours post op (600 min) half of the patient (16) in Group B did not required analgesics, whereas all the patients required analgesics in Group A. This shows that Group B had better analgesia post operatively as compared to Group A.

\section{DISCUSSION}

There are different approaches of the brachial plexus block. Interscalene approach is widely used method for anaesthesia because, plexus is superficial, easily accessible, and there is less chance of pneumothorax. Interscalene approach is used for anaesthesia and perioperative pain management in surgery of shoulder joint. In our study, mean duration of analgesia was longer in Group B (688.75 $33.219 \mathrm{~min})$ as compared to Group A $(275.75 \pm 24.27 \mathrm{~min})$. Gandhi $\mathrm{R}$ et al. ${ }^{4}$ stated that duration of analgesia in Dexmedetomidine group $(732.4 \pm 95.1 \mathrm{~min})$ was longer when compared to control group (194.8 $\pm 60.4 \mathrm{~min})$. Swami SS et al. ${ }^{5}$ in their study showed that duration of analgesia in Dexmedetomidine group (456.21 $\pm 9.7 \mathrm{~min})$ was longer than clonidine group (289.67 $\pm 62.5 \mathrm{~min})$. Hussain $\mathrm{N}$ et al. ${ }^{6}$ compared the ability of dexmedetomidine to prolong the duration and hasten the onset of motor and sensory blockade when used as an adjuvant to local anesthesia for brachial plexus blockade versus using local anesthesia alone (control). In this study, dexmedtomidine group had significant prolongation of duration of analgesia by 289.31 minutes (95\% CI, 185.97 392.64 minutes; I $=99 \%$; P $<0.00001$ ) than the control group which used local anaesthetic alone. Ammar AS et $a .^{7}$ conducted a study to test the efficacy of adding Dexmedetomidine to bupivacaine during placement of ultrasound guide Infraclavicular brachial plexus blockade. In this study, duration of analgesia was 403 compared to $233 \mathrm{~min}$ in the control group. In present study, there was significant difference between median VAS score in Group A and Group B. Group B has significantly less VAS score compared to Group A $(\mathrm{p}<0.0001)$ Group B patients required less rescue analgesics as compared to Group A patients during first 24 hour postoperatively. An initial intravenous dose of $1.0 \mu \mathrm{g} / \mathrm{kg}$ dexmedetomidine for 10 $\mathrm{min}$, followed by a continuous infusion of $0.7 \mu \mathrm{g} / \mathrm{kg} / \mathrm{h}$ approximately $15 \mathrm{~min}$ before the induction of general anesthesia, may be a novel and effective treatment option for preventing or attenuating opioid-induced hyperalgesia. ${ }^{8}$ One study reported that dexmedetomidine led to a decreased requirement for opioid analgesics and inhaled anesthetics, and lessened the incidence of severe changes of circulation during traumatic phases of surgeries. ${ }^{9}$ Adding $1 \mu \mathrm{g} / \mathrm{kg}$ dexmedetomidine to $0.75 \%$ ropivacaine in 35 patients undergoing arthroscopic shoulder surgery with ultrasound-guided single-dose interscalene block prolonged the interscalene block, and provided better postoperative pain control during the first $24 \mathrm{~h}$, compared to that produced by clonidine. ${ }^{10}$ The addition of $2 \mathrm{~mL}$ of $0.5 \mu \mathrm{g} / \mathrm{kg}$ dexmedetomidine to $20 \mathrm{~mL}$ of $0.3 \%$ ropivacaine for ultrasound-guided bilateral transversus abdominis plane block for postoperative analgesia after abdominal hysterectomy surgery potentiated the analgesic properties of ropivacaine, reduced sufentanil consumption, and provided better pain control. ${ }^{11}$

\section{CONCLUSION}

Addition of dexmedetomidine to bupivacaine as an adjuvant is a promising option to enhance their effectiveness. So, the patient remains comfortable in the postoperative period with considerable therapeutic benefit and without any potential side effects. 


\section{REFERENCES}

1. Rawal N, Hylander J, Nydahl PA, Olofsson I, Gupta A. Survey of postoperative analgesia following ambulatory surgery. Acta Anaesthesiol Scand 1997;41:1017-22.

2. Ghansham Biyani, Anjolie Chhabra, Dalim Kumar Baidya, Rahul Kumar Anand. Adjuvants to local anaesthetics in regional anaesthesia - Should they be used? Part I: Pros. Trends in Anaesthesia and Critical Care 4.2014;19-24. iscepi

3. Lennart Christiansson. Update on adjuvants in regional anaesthesia. Periodicum biologorum. 2009;111(2):161170.

4. Gandhi R, Shah A, Patel I. Use of dexmedetomidine along with bupivacaine for brachial plexus block. National J Med Res 2012;2:67-9.

5. Swami SS, Keniya VM, Ladi SD, Rao R. Comparison of dexmedetomidine and clonidine (alpha-2 agonist drugs) as an adjuvant to local anaesthesia in supraclavicular brachial plexus block: randomised double-blind prospective study. Indian J Anaesth 2012 May;56(3):243-9.

6. Hussain N, Grzywacz VP, Ferreri CA, Atrey A, Banfield L, Shaparin N, Vydyanathan A. Investigating the Efficacy of Dexmedetomidine as anAdjuvant to Local Anesthesia in Brachial PlexusBlock: A Systematic Review and MetaAnalysis of 18Randomized Controlled Trials. Reg Anesth Pain Med. 2017 Mar/Apr;42(2):184-196.
7. Ammar AS, Mahmoud KM. Ultrasound-guided single injection infraclavicular brachial plexus block using bupivacaine alone or combined with dexmedetomidine for pain control in upper limb surgery: a prospective randomized controlled trial. Saudi J Anaesth 2012;6:10914.

8. Lee C, Kim YD, Kim JN. Antihyperalgesic effects of dexmedetomidine on high-dose remifentanil-induced hyperalgesia. Korean J Anesthesiol. 2013;64(4):301-307.

9. Volkov PA, Churadze BT, Sevalkin SA, Volkova YN, Guryanov VA. [Dexmedetomidine as a part of analgesic component of general anesthesia for laparoscopic operations]. Anesteziol Reanimatol. 2015;60(1):4-8. Russian [with English abstract].

10. Velázquez-Delgado E, Gaspar-Carrillo SP, Peña-Riveron AA, Mejía-Terrazas GE. [Postoperative analgesia with dexmedetomidine in interscalene block. Comparative study]. Rev Esp Anestesiol Reanim. 2017;64(3):137-143. Spanish [with English abstract].

11. Luan H, Zhang X, Feng J, Zhu P, Li J, Zhao Z. Effect of dexmedetomidine added to ropivacaine on ultrasoundguided transversus abdominis plane block for postoperative analgesia after abdominal hysterectomy surgery: a prospective randomized controlled trial. Minerva Anestesiol. 2016;82(9):981-988.

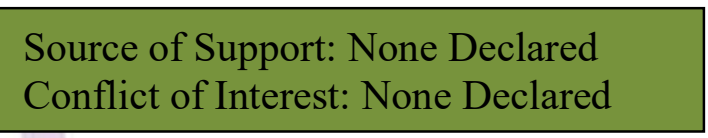

Policy for Articles with Open Access:

Authors who publish with MedPulse International Journal of Anesthesiology (Print ISSN:2579-0900) (Online ISSN: 2636-4654) agree to the following terms: Authors retain copyright and grant the journal right of first publication with the work simultaneously licensed under a Creative Commons Attribution License that allows others to share the work with an acknowledgement of the work's authorship and initial publication in this journal.

Authors are permitted and encouraged to post links to their work online (e.g., in institutional repositories or on their website) prior to and during the submission process, as it can lead to productive exchanges, as well as earlier and greater citation of published work. 